\title{
Induction of apoptosis in oral squamous carcinoma cells by pyrrolo-1,5-benzoxazepines
}

\author{
KATE O'CALLAGHAN $^{1}$, ELEONORA PALAGANO ${ }^{2}$, STEFANIA BUTINI ${ }^{3}$, GIUSEPPE CAMPIANI ${ }^{3,4}$, \\ D. CLIVE WILLIAMS ${ }^{2}$, DANIELA M. ZISTERER ${ }^{2}$ and JEFF O'SULLIVAN ${ }^{1}$ \\ ${ }^{1}$ School of Dental Science, Trinity College Dublin; ${ }^{2}$ School of Biochemistry and Immunology, Trinity Biomedical Sciences Institute, \\ Trinity College Dublin, Dublin 2, Ireland; ${ }^{3}$ Department of Drug Chemical Technology, University of Siena, Siena 53100; \\ ${ }^{4}$ European Research Centre for Drug Discovery and Development (NatSynDrugs), Siena 53100, Italy
}

Received May 9, 2014; Accepted April 30, 2015

DOI: $10.3892 / \mathrm{mmr} .2015 .3832$

\begin{abstract}
Oral cancer (OC) is a largely asymptomatic disease, resulting in one of the highest mortality rates of any cancer. OC is currently ranked as the sixth most common cancer in the world, according to a recent World Health Organization analysis, and its prevalence is increasing, both in western and developing regions. Depending on the stage of OC, treatment strategies include surgery, radiation therapy and chemotherapy, or a combination thereof. As with numerous other types of cancer, resistance to conventional chemotherapeutic drugs is increasing in oral squamous cell carcinoma (OSCC). The present study aimed to investigate the use of a novel group of compounds, the pyrrolo-1,5-benzoxazepines (PBOXs), as a therapeutic alternative for the treatment of OC. PBOXs are microtubule-targeting agents that are able to induce apoptosis in numerous cancer cell types, thereby preventing tumour cell proliferation. Ca9.22 gingival and TR146 buccal cell lines were used as models for OSSC. Cell viability and proliferation in the presence of two PBOXs: PBOX-6 and PBOX-15, was monitored using an AlamarBlue $\mathrm{e}^{\mathrm{TM}}$ assay. Flow cytometric analysis of propidium iodide-stained cells was used to determine the DNA content, and therefore the percentage of cells in each phase of the cell cycle. Microtubule disruption was determined by indirect immunofluorescence staining. Changes in protein expression and degradation were determined by western blotting. The results of the present study indicated that both PBOX-6 and -15 were able to induce apoptotic cell death by disrupting the microtubule network in both cell lines. The $\mathrm{EC}_{50}$ values were subsequently calculated for both PBOX-6 and -15 , and PBOX-15 was shown to possess a higher potency. Both compounds displayed anti-proliferative effects mediated
\end{abstract}

Correspondence to: Dr Kate O'Callaghan, School of Dental Science, Trinity College Dublin, College Green, 2 Lincoln Place, Dublin 2, Ireland

E-mail: ocallaka@tcd.ie

Key words: pyrrolo-1,5-benzoxazepines, microtubule-targeting agents, oral cancer through sustained $\mathrm{G}_{2} / \mathrm{M}$ arrest accompanied by tubulin disruption, and a decrease in DNA repair protein poly (ADP ribose) polymerase expression. These findings suggest that PBOXs may prove useful, either alone or in combination with other agents, in the treatment of chemotherapeutic resistant OSCC.

\section{Introduction}

Oral cancer (OC) is the sixth most common cancer worldwide and has one of the highest mortality rates, due to it being largely asymptomatic until the latter stages of the disease. Cancers of the oral cavity include cancers that occur in the tongue, floor of the mouth, buccal mucosa, alveolus, retromolar trigone, gingival, hard palate, and lips (1,2). A total of $90 \%$ of OCs are squamous cell carcinomas (SCC) (3). SCC is caused by the presence of malignant cells in the epithelium. Oral SCC (OSCC) accounts for 2-3\% of all malignancies, the prevalence of which ranges between 1-10 cases per 100,000 people in the majority of countries (4).

OSCC prognosis is poor, with a 5-year survival rate of $\sim 50 \%$, according to the National Cancer Research Institute (5). Treatments for OSCC are usually limited to a combination of chemotherapy and radiation, in order to reduce tumour size prior to the surgical removal of the tumour margins. Two of the most common chemotherapeutic agents used in the treatment of OSCC are cisplatin and 5-fluorouracil (6), and recurrent tumours are usually treated with one of these two chemotherapy drugs. However, resistance to these drugs may develop following treatment, as is the case in numerous types of cancer $(7,8)$.

Pyrrolo-1,5-benzoxazepines (PBOXs) are a novel family of compounds that have been shown to induce cell cycle arrest and apoptosis in numerous cancer cell lines, including chemotherapy-resistant cell lines $(9,10)$. In addition, PBOXs have been shown to induce cell apoptosis in ex vivo patient samples and in in vivo animal models of breast cancer and chronic myeloid leukaemia $(10,11)$. Notably, PBOXs display minimal toxicity towards normal blood and bone marrow cells (12). A recently improved understanding regarding the molecular mechanisms underlying the apoptotic effects of PBOX compounds has allowed their development as antineoplastic therapeutic agents. Within the PBOX family, two 
members exhibit markedly elevated activity, PBOX-6 and PBOX-15 (Fig. 1) (10).

Mulligan et al (13) previously demonstrated that PBOX-induced apoptosis in cancer cells is preceded by a marked $\mathrm{G}_{2} / \mathrm{M}$ phase cell cycle arrest, and that the cells displayed morphological features that suggested an inhibition of mitosis, notably in pro-metaphase. The effects of PBOXs on cell morphology are similar to those induced by two microtubule-targeting drugs, paclitaxel and nocodazole, which are polymerising and depolymerising agents, respectively. These results are concordant with previous studies that also demonstrated that anti-microtubule agents arrest the cell cycle in pro-metaphase $(14,15)$.

Previous studies have suggested that PBOXs possess anti-microtubule activity. Through indirect immunofluorescence analysis, Mulligan et al (13) demonstrated that pro-apoptotic PBOX compounds result in depolymerisation of the microtubule network, and an inhibition of the assembly of purified tubulin in vitro. Tubulin has therefore been identified as the molecular target of the pro-apoptotic PBOX compounds (15).

In the present study the pro-apoptotic capabilities of two representative members of the PBOX family, PBOX-6 and PBOX-15, were examined in the TR146 (buccal mucosa) and Ca9.22 (gingival carcinoma) cell lines. The aim of the present study was to investigate the potential of these compounds on inhibiting the proliferation of OSCC cells. The present study also examined the cell death mechanism and efficacy of the compounds and aimed to determine the effectiveness of the compounds against OSCC cells with differing genotypes. Together, the results from the present study may indicate the potential of the PBOX compounds in the treatment of OSCC, and whether there is in merit further investigation, either alone, or in combination with other agents as a potential treatment modality for OC.

\section{Materials and methods}

Reagents. All reagents were obtained from Sigma-Aldrich (Arklow, Ireland) unless otherwise stated. The PBOX compounds, 7-[(N,N-dimethycarbomoyl) oxy]-6-(naphth-1-yl) pyrrolo[2,1-d][1,5]benzoxazepine (PBOX-6), and 4-acetoxy-5(naphth-1-yl)naphtho[2,3-b] pyrrolo[2,1-d][1,4]oxazepine (PBOX-15), were synthesized as previously described (16). The PBOX compounds were subsequently dissolved in $1 \%$ ethanol, and stored at $-20^{\circ} \mathrm{C}$. The antibodies used in the present study were as follows: Mouse anti-human/rat/mouse anti- $\alpha$-tubulin (cat. no. CP06; EMD Millipore, Billerica, MA, USA); mouse anti-human anti-poly (ADP ribose) polymerase (PARP; cat. no. MABC547; Merck Biosciences Ltd., Nottingham, UK); and mouse anti- $\beta$-actin (cat. no MAB1501; EMD Millipore).

Cell culture. Both cell lines were maintained in a $95 \%$ humidified atmosphere containing $5 \% \mathrm{CO}_{2}$ at $37^{\circ} \mathrm{C}$, and all cell culture experiments were carried out under sterile conditions in a laminar flow hood. Cell growth and viability were visually monitored using a light microscope (Nikon Eclipse TS100; MicronOptical, Wexford, Ireland) with 10 and 20x dry objectives. The TR146 cell line was initially derived from the neck node of a 67 year-old female (the primary tumour was located in the buccal mucosa) and was obtained from the Health Protection Agency Culture Collection (Salisbury, UK). The TR146 cells were maintained in Dulbecco's Modified Eagle's medium, supplemented with $10 \% \mathrm{v} / \mathrm{v}$ foetal bovine serum (FBS), $10 \mathrm{U} / \mathrm{ml}$ penicillin, $0.1 \mathrm{mg} / \mathrm{ml}$ streptomycin, and $2 \mathrm{mM}$ glutamine. The $\mathrm{Ca} 9.22$ cell line was obtained from the Japanese Collection of Research Bioresources Cell Bank (Osaka, Japan). The Ca9.22 cells were maintained in Minimum Essential medium, supplemented with $10 \%$ v/v FBS, $10 \mathrm{U}$ penicillin, $0.1 \mathrm{mg} / \mathrm{ml}$ streptomycin, and $2 \mathrm{mM}$ glutamine. All control cells were treated with vehicle ( $1 \%$ ethanol) alone.

Cell proliferation. Cell proliferation was determined using AlamarBlue ${ }^{\mathrm{TM}}$ dye (Life Technologies, Grand Island, NY, USA), which allowed the visualisation of changes in compound fluorescence that occur as a consequence of the reduced number of viable, proliferating cells. The cells were seeded in 96-well plates for each of the time points with specified concentrations of PBOX-6 (10 nM-100 $\mu \mathrm{M})$ or PBOX-15 $(1 \mathrm{nM}-250 \mu \mathrm{M})$, and were incubated at $37^{\circ} \mathrm{C}$ in $5 \% \mathrm{CO}_{2}$. A final concentration of $10 \%(\mathrm{v} / \mathrm{v})$ AlamarBlue ${ }^{\mathrm{TM}}$ was added to the cells $4 \mathrm{~h}$ prior to the end of each time point. Fluorescence was measured at an excitation wavelength of $544 \mathrm{~nm}$ and at an emission wavelength of $590 \mathrm{~nm}$, using a SpectraMax Gemini spectrofluorometric plate reader (Molecular Devices (UK) Ltd, Wokingham, UK). Cell viability was determined as a percentage of the vehicle-only cells. The experimental results were displayed as dose-response curves and half maximal effective concentration $\left(\mathrm{EC}_{50}\right)$ values, as determined using Prism GraphPad 5 (GraphPad Software, Inc., La Jolla, CA, USA).

Immunofluorescence. The cells were cultured for $24 \mathrm{~h}$ on $13 \mathrm{~mm}$ glass coverslips with the following seed densities:

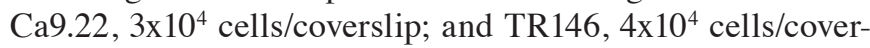
slip. The cells were subsequently cultured in the presence of either PBOX-6 or PBOX-15 for a further 24 h. Following incubation, the cells were fixed with $4 \%$ paraformaldehyde in phosphate-buffered saline (PBS) for $15 \mathrm{~min}$, permeabilised with $0.2 \%$ Triton in PBS for $10 \mathrm{~min}$, rinsed with PBS, and blocked using $1 \%$ bovine serum albumin (BSA) in PBS containing Tween ${ }^{\circledR} 20$ (PBST) for $30 \mathrm{~min}$. The cells were then incubated with the following primary antibodies: Mouse anti- $\alpha$-tubulin $(1: 1,000)$ in $1 \%$ BSA and PBST for $1 \mathrm{~h}$, prior to incubation with secondary goat anti-mouse antibody 488 (cat. no. a-11001; Life Technologies; 1:500) in 1\% BSA and PBST for $1 \mathrm{~h}$. The coverslips were then placed on glass slides with $3.5 \mu \mathrm{l}$ Vectashield ${ }^{\mathrm{TM}}$ mounting medium (Vector Labs, Burlingame, CA, USA) containing the nuclear counterstain 4,6-diamidino-2-phenylindole (DAPI), and stored in the dark at $4^{\circ} \mathrm{C}$ until imaging. The indirect fluorescence of the cells was examined using a standard filter set for DAPI and blue/green, through 10 and 20x dry objectives, and a 60x oil objective using a Zeiss Axiovert/Axiocam CCD system, and imaged using AxioVision AxioVs40 software (Carl Zeiss Ltd., Cambridge, UK).

DNA content. The cellular DNA content was determined using of propidium iodide (PI), an intercalating fluorescent dye. The fluorescence intensity is proportional to the quantity 

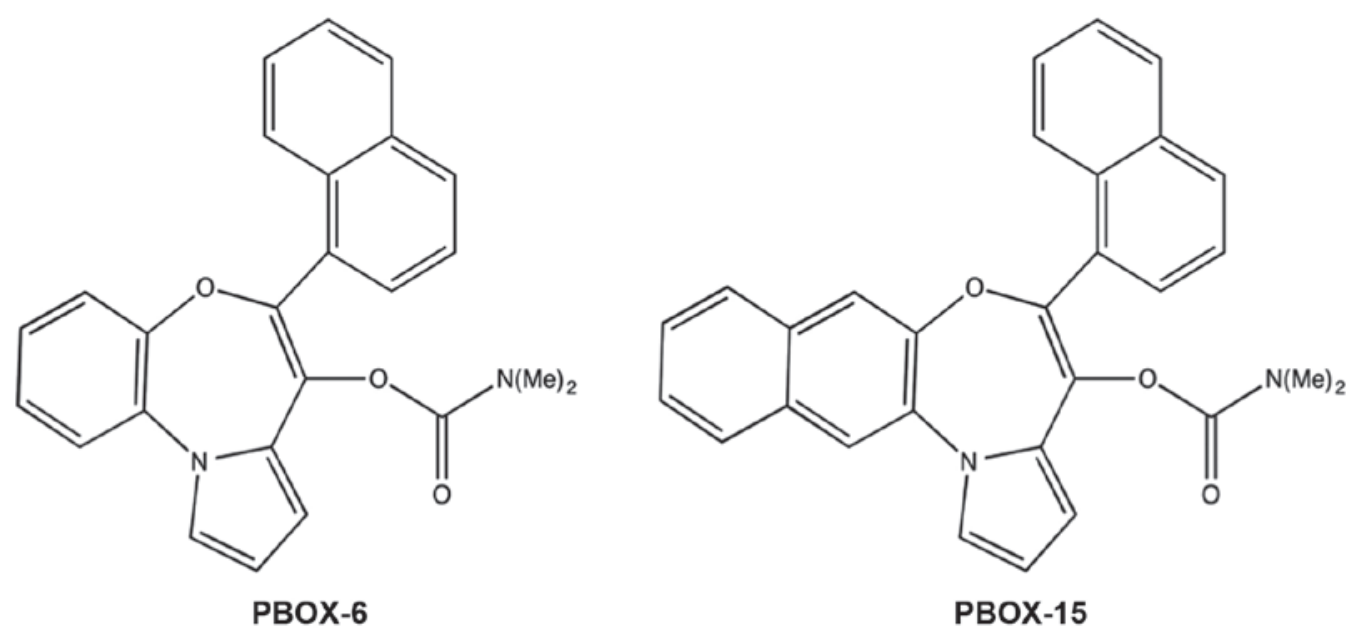

Figure 1. Chemical structures of pyrrolo-1,5-benzoxazepine (PBOX)-analogues PBOX-6 and PBOX-15.

of DNA present in the cell. Both cell lines were cultured in the presence of PBOX- 6 or PBOX-15 at the desired concentrations and time points. The cells were then harvested by trypsinisation, prior to being centrifuged at $220 \mathrm{x}$ g for $5 \mathrm{~min}$, washed with PBS, and centrifuged once more. The supernatant was decanted and the cell pellets were resuspended in $200 \mu \mathrm{l}$ PBS, prior to the addition of $2 \mathrm{ml}$ ice-cold $70 \%$ ethanol in order to fix the cells. Following overnight fixation at $4^{\circ} \mathrm{C}$, the cells were centrifuged at $200 \mathrm{x} \mathrm{g}$ for $5 \mathrm{~min}$ in order to remove the ethanol, and the pellet was resuspended in $400 \mu \mathrm{l}$ PBS, followed by $25 \mu \mathrm{l}$ RNase A, and $75 \mu \mathrm{l}$ PI. The cells were incubated in the dark at $37^{\circ} \mathrm{C}$ for $30 \mathrm{~min}$. The samples were subsequently transferred to appropriately labeled fluorescence activated cell sorting (FACS) tubes, and were analysed using a FACSCalibur flow cytometer (BD Biosciences, Oxford, UK). The fluorescent signal was detected using a 630-22 $\mathrm{nm}$ band pass filter (FL2). The cell lines were gated in order to prevent cell debris and doublets from being counted. A total of $>10,000$ cells were counted and analysed using Treestar FlowJo v10 (FlowJo, Oregon, OR, USA).

Analysis of protein expression by western blotting. The cells cultured in the presence of PBOX-6 or PBOX-15 for 24, 48 , and $72 \mathrm{~h}$, were harvested and centrifuged at $220 \mathrm{x}$ g for $5 \mathrm{~min}$, following which the supernatants were discarded and the cell pellets were resuspended in $2 \mathrm{ml}$ ice-cold PBS. Following further centrifugation at $220 \mathrm{x} \mathrm{g}$ for $5 \mathrm{~min}$, the supernatant was removed and the pellets were resuspended in $80 \mu \mathrm{l}$ ice-cold lysis buffer $(150 \mathrm{mM}$ sodium chloride, $1.0 \%$ Triton X-100, 50 mM Tris; pH 8.0) containing Complete Protease Inhibitor Cocktail (Roche Diagnostics Ltd., Burgess Hill, UK). The samples were maintained under constant agitation at $1,000 \mathrm{rpm}$ for $30 \mathrm{~min}$ at $4^{\circ} \mathrm{C}$, prior to being centrifuged at $13,000 \mathrm{x} \mathrm{g}$ for $20 \mathrm{~min}$ at $4^{\circ} \mathrm{C}$. The supernatants were aspirated and placed in an eppendorf tube on ice until further experimentation. The protein concentrations were deterxwmined using a bicinchoninic acid assay. The protein samples were separated by SDS-PAGE with an $8 \%$ resolving gel. The proteins were then transferred to a polyvinylidene difluoride (PVDF) membrane using a semi-dry blotter for $1 \mathrm{~h}$. The PVDF membranes were subsequently blocked with $5 \%$ non-fat milk, and probed with the appropriate primary antibodies prior to being incubated with horseradish peroxidase-conjugated goat anti-mouse secondary antibody (cat. no. sc2031; Santa Cruz Biotechnology, Inc., Santa Cruz, CA, USA). Protein expression was visualised through chemiluminescence using an Immobilon Western Chemiluminescent HRP substrate (Merck Millipore, Darmstadt, Germany).

Statistical analysis. Statistical significance was determined using Prism GraphPad 5 (GraphPad Software, La Jolla, CA, USA). Analysis was performed using an unpaired t-test with post-hoc Bonferroni analysis. $\mathrm{P}<0.001$ was considered to indicate a statistically significant difference.

\section{Results}

PBOX compounds reduce OC cell proliferation. The OSCC cell lines were treated for $72 \mathrm{~h}$ with PBOX-6 or PBOX-15 at various concentrations. Cell proliferation was subsequently measured using AlamarBlue ${ }^{\mathrm{TM}}$ assay. The results of the assay indicated that PBOX-6 and PBOX-15 reduced proliferation of both the Ca.922 and the TR146 cell lines in a dose-dependent manner (Fig. 2). PBOX-15 was the more potent of the two analogues. After $72 \mathrm{~h}$, the $\mathrm{EC}_{50}$ values of PBOX- 6 and PBOX-15 were $35 \pm 2.7 \mu \mathrm{M}$ and $470 \pm 86 \mathrm{nM}$ for the TR146 cells, and $2.6 \pm 1 \mu \mathrm{M}$ and $83 \pm 32 \mathrm{nM}$ for the Ca9.22 cells, respectively (Table I). The drug concentrations used for the remaining experiments were chosen according to the results of this cell proliferation assay.

PBOX compounds destabilise and depolymerise the microtubule network in OC cells. The Ca9.22 and TR146 cells were treated with either PBOX-6 or PBOX-15 for $24 \mathrm{~h}$. In addition, the cells were also treated with the known tubulin polymeriser, paclitaxel $(1 \mu \mathrm{mol} ; 24 \mathrm{~h})$, and the tubulin depolymeriser, nocodazole $(10 \mu \mathrm{mol} ; 24 \mathrm{~h})$, both purchased from Sigma-Aldrich, which served as positive controls. Immunofluorescent staining was used to detect morphological changes in the microtubule network, such as alterations in microtubule organisation and arrangement 
Table I. Half maximal effective concentration $\left(\mathrm{EC}_{50}\right)$ values obtained for each pyrrolo-1,5-benzoxazepine (PBOX) compound in the TR146 and Ca9.22 oral squamous cell carcinoma cell lines.

\begin{tabular}{lccc}
\hline & \multicolumn{1}{c}{$\mathrm{EC}_{50}$} & $72 \mathrm{~h}$ \\
\cline { 2 - 4 } Cell line & $24 \mathrm{~h}$ & $48 \mathrm{~h}$ & \\
\hline TR146 & & & $35 \pm 2.7 \mu \mathrm{M}$ \\
PBOX-6 & $9.2 \pm 2.3 \mu \mathrm{M}$ & $8.1 \pm 0.3 \mu \mathrm{M}$ & $470 \pm 86 \mathrm{nM}$ \\
PBOX-15 & $480 \pm 92 \mathrm{nM}$ & $530 \pm 52 \mathrm{nM}$ & $2.6 \pm 1 \mu \mathrm{M}$ \\
Ca9.22 & & & $83 \pm 32 \mathrm{nM}$ \\
PBOX-6 & $4.5 \pm 1.5 \mu \mathrm{M}$ & $2.9 \pm 0.7 \mu \mathrm{M}$ & $170 \pm 81 \mathrm{nM}$ \\
PBOX-15 & $210 \pm 28 \mathrm{nM}$ & & \\
\hline
\end{tabular}

A

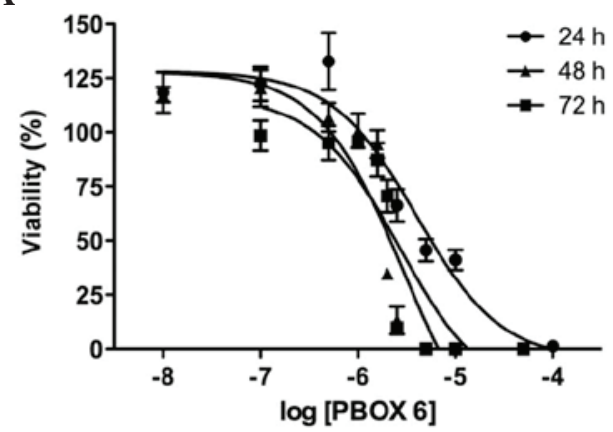

C

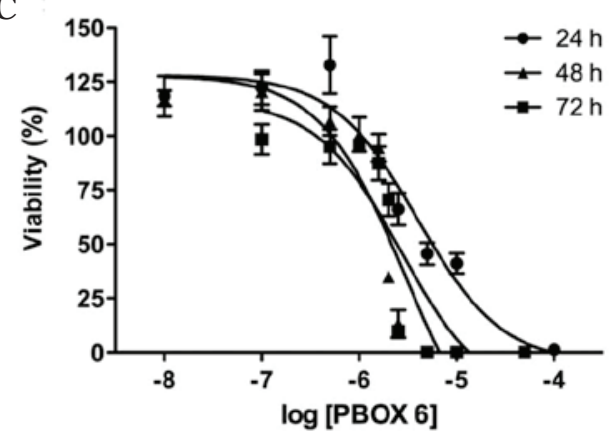

B
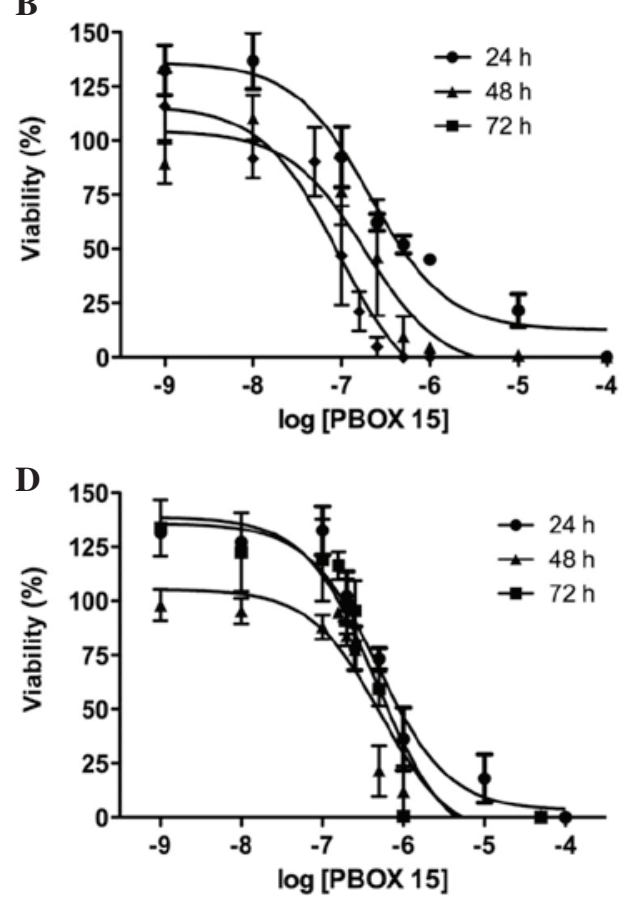

Figure 2. Pyrrolo-1,5-benzoxazepines (PBOX)-6 and PBOX-15 reduce the viability of oral squamous cell carcinoma (OSCC) cell lines. OSCC cell lines (A and B) TR146 and (C and D) Ca9.22 were treated with a range of (A and C) PBOX-6 and (B and D) PBOX-15 for 24, 48, and 72 h. AlamarBlue ${ }^{\mathrm{TM}}$ was added $4 \mathrm{~h}$ prior to endpoint reading. Fluorescence was measured using a Spectramax Gemini Plate reader at excitation and emission wavelengths of 544 nm and $590 \mathrm{~nm}$, respectively. The values are presented as the mean \pm standar error of the mean for three independent experiments.

(Fig. 3). In the vehicle TR146 (Fig. 3A) and Ca9.22 (Fig. 3B) cells, the microtubule network was organised as cytoplasmic tubulin filaments radiating from a central point to the periphery. Exposure of the cells to the tubulin polymerising agent paclitaxel resulted in a highly concentrated accumulation of filaments in dense peripheral bundles, indicative of microtubule stabilisation. Conversely, exposure to the tubulin depolymerising agent nocodazole resulted in diffuse tubule staining with no definition of structure caused by microtubule disassembly. No alterations in microtubule structure were evident following treatment with a low dose of $100 \mathrm{nM}$ PBOX-6 and PBOX-15, whereas higher doses of $10 \mu \mathrm{M}$ PBOX-6 and $1 \mu \mathrm{M}$ PBOX-15 resulted in a change in tubulin morphology resembling that induced by nocodazole. These results indicate that PBOX compounds destabilise the microtubule network in a similar manner to a depolymerising agent, in both TR146 and Ca9.22 cell lines.

In order to confirm the results of previous studies, namely that the disruption observed using a confocal microscope is the result of depolymerisation of the tubulin network, tubulin polymerisation assays were performed using western blotting (Fig. 3C). Following $4 \mathrm{~h}$ treatment with $10 \mu \mathrm{M}$ PBOX-6 or $1 \mu \mathrm{M}$ PBOX-15, tubulin was shown to be completely depolymerised in both cell lines. Following $4 \mathrm{~h}$ treatment with paclitaxel, tubulin was polymerised, whereas treatment with nocozadole resulted in unpolymerised tubulin. Treatment with the vehicle $(1 \% \mathrm{EtOH})$ resulted in equal amounts of polymerised to unpolymerised tubulin. These results indicate that the disruption observed by confocal microscopy was indeed depolymerisation of the tubulin network. 
A

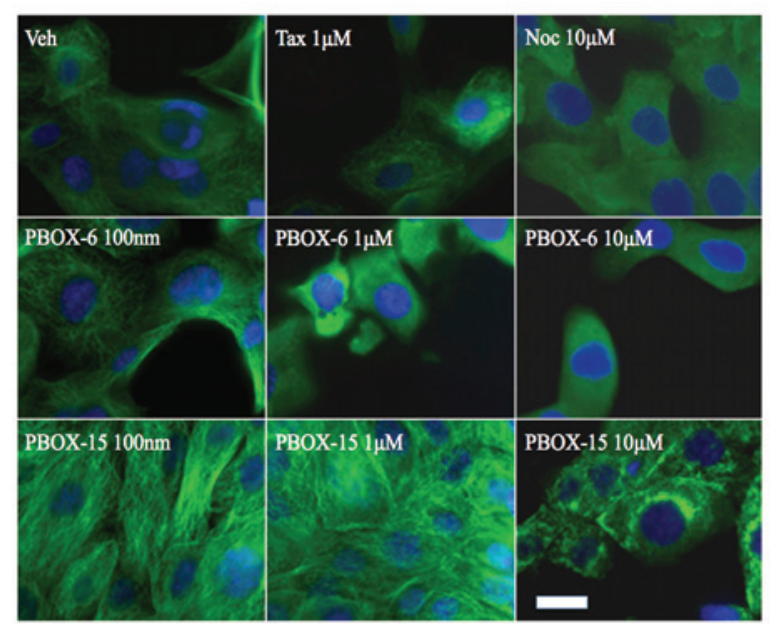

B

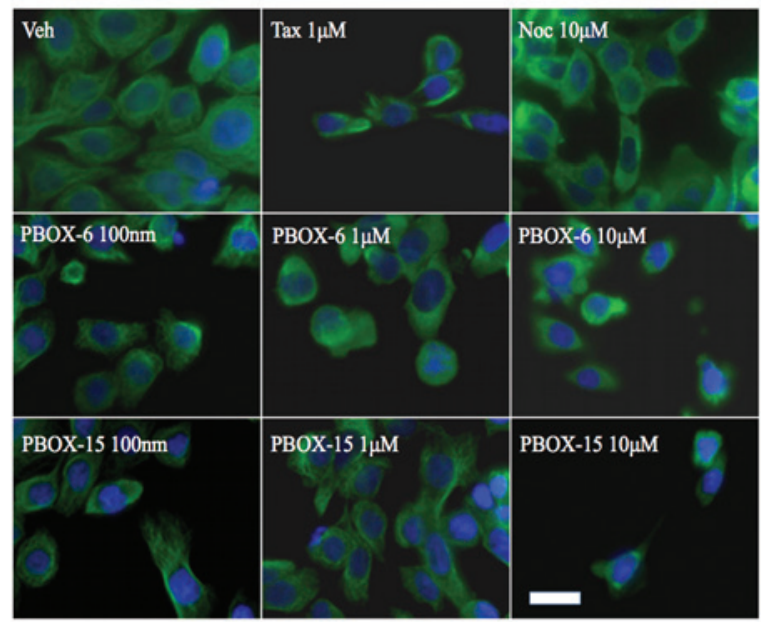

C

$\frac{V \text { Vh }}{U P} \frac{\text { Tax }}{U P} \frac{\text { Noc }}{U P B O X-6 \text { PBOX-15 }} \frac{\text { PB }}{U P}$

TR146

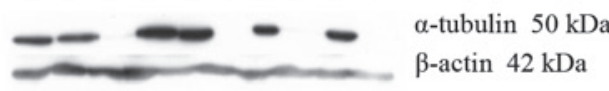

$\mathrm{Ca} 9.22$

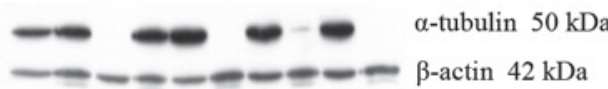

Figure 3. Pyrrolo-1,5-benzoxazepines (PBOX)-6 and PBOX-15 induce microtubule disruption and depolymerisation of oral squamous cell carcinoma (OSCC) cell lines. (A) TR146 and (B) Ca9.22 cells were treated with either vehicle, $1 \mu \mathrm{M}$ paclitaxel (Tax), $10 \mu \mathrm{M}$ nocodazole (Noc), $100 \mathrm{nM}, 1 \mu \mathrm{M}$ or $10 \mu \mathrm{M}$ PBOX-15, or $100 \mathrm{nM}, 1 \mu \mathrm{M}$ or $10 \mu \mathrm{M}$ PBOX-6 for $24 \mathrm{~h}$. The medium was subsequently removed and the cells were fixed with paraformaldehyde. The cells were then incubated with monoclonal anti- $\alpha$-tubulin antibody, followed by further incubation with fluorescein isothiocyanate-conjugated anti-mouse secondary antibody. The organization of the microtubule network (green) and the cellular DNA (blue) was visualized using a Zeiss Axiovert/Axiocam CCD system through 10x and 20x dry objectives, and a 60x oil objective. Scale bar, $20 \mu \mathrm{m}$. (C) In order to confirm tubulin depolymerisation in the TR146 and Ca9.22 cell lines, the cells were treated for $4 \mathrm{~h}$ with either vehicle (1\% (v/v) ethanol), PBOX-6 $(10 \mu \mathrm{M})$, PBOX-15 $(1 \mu \mathrm{M})$, Tax $(1 \mu \mathrm{M})$, or Noc $(10 \mu \mathrm{M})$, The polymerised $(\mathrm{P})$ or unpolymerised $(\mathrm{U})$ tubulin was then separated by centrifugation in a microtubule-preserving buffer. The ratio of polymerised, vs. unpolymerised tubulin was subsequently assessed by western blot analysis using monoclonal antibodies directed against tubulin and loading control $\beta$-actin, followed by incubation with horseradish peroxidase-conjugated anti-mouse antibody. The images are representative of experiments repeated three times.

PBOX compounds induce $G_{2} / M$ arrest and apoptosis in $O C$ cells. The DNA content of the PI-stained TR146 and Ca9.22 cells was measured using flow cytometric analysis, thus allowing the successful identification of cell cycle arrest or apoptosis. A decrease in the number of cells in the $G_{2} / M$ phase of the cell cycle was observed in both cell lines following $8 \mathrm{~h}$ treatment with PBOX-6 (10 $\mu \mathrm{M})$ and PBOX-15 (1 $\mu \mathrm{M})$ (Fig. 4C and 4D). A marked decrease was observed in the number of TR146 cells arrested in $\mathrm{G}_{2} / \mathrm{M}$ phase following $72 \mathrm{~h}$ treatment, $15.4 \pm 1.07 \%$ and $12.6 \pm 1.87 \%$ for PBOX-6 and -15 , respectively. A significant decrease also occurred in the number of Ca9.22 cells arrested in the $\mathrm{G}_{2} / \mathrm{M}$ phase following $72 \mathrm{~h}$ of treatment, $22.23 \pm 0.95 \%$ and $16.6 \pm 1.25 \%$ for PBOX-6 and PBOX-15, respectively. This decline in the levels of $\mathrm{G}_{2} / \mathrm{M}$ phase cells correlated with a marked increase in the number of apoptotic TR146 cells, with the levels of apoptosis rising to $4.4 \pm 1.210 \%$ in the control cells, $57.6 \pm 8.1 \%$ in the cells treated with $10 \mu \mathrm{M}$ PBOX-6, and $39.1 \pm 6.6 \%$ in the cells treated with $1 \mu \mathrm{M}$ PBOX-15 (Fig 4A and 4B). Similarly, in the Ca9.22 cell line, the number of cells in the sub- $\mathrm{G}_{0} / \mathrm{G}_{1}$ phase following $72 \mathrm{~h}$ increased to $2.120 \pm 0.8 \%$ in the control cells, $40.84 \pm 0.8 \%$ in the cells treated with PBOX-6, and $30.45 \pm 1.56 \%$ in the cells treated with PBOX-15. A decrease in the number of cells in the $\mathrm{G} 2 / \mathrm{M}$ phase of the cell cycle were observed in each cell line following $8 \mathrm{~h}$ treatment with PBOX-6 $(10 \mu \mathrm{M})$ and PBOX-15 (1 $\mu \mathrm{M}$; Fig. 4C and 4D).
PBOX compounds induce degradation of PARP in OC cell lines. In order to confirm that the cell death observed during flow cytometric analysis was indeed cellular apoptosis, PARP degradation, which is associated with controlled cell death, was assessed. Concordant with the DNA content analysis results, both PBOX-6 $(10 \mu \mathrm{M})$ and PBOX-15 $(1 \mu \mathrm{M})$ induced a decrease in the expression levels of full length PARP in Ca9.22 and TR146 cells following $72 \mathrm{~h}$ treatment (Fig. 4E and 4F). Treatment with the vehicle $(1 \%(\mathrm{v} / \mathrm{v})$ EtOH) did not affect PARP expression in either cell line. In the TR146 cell line, PARP degradation was observed following $24 \mathrm{~h}$ treatment with $1 \mu \mathrm{M}$ PBOX-15, as compared with the vehicle control. PARP degradation was clearly observed in the TR146 cell line following $48 \mathrm{~h}$ treatment with both PBOX compounds. In addition, PARP degradation was also observed in the Ca9.22 cell line following $48 \mathrm{~h}$ treatment with both PBOX compounds. $\beta$-actin was used as a loading control in all experiments. These results indicate that the PBOX compounds induce apoptosis via tubulin disassembly.

\section{Discussion}

The present study assessed a novel set of compounds with regards to their potential therapeutic value in OC. PBOX-15 and PBOX-6 are potent pro-apoptotic members of the PBOX family, and have previously been shown to induce apoptosis 
A TR146

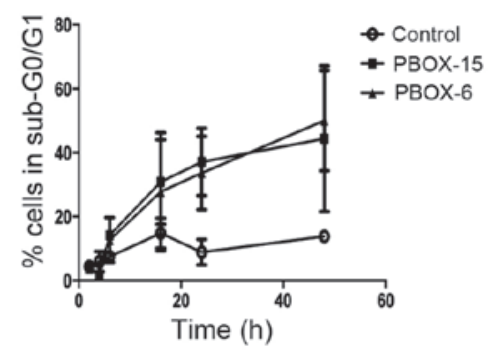

C

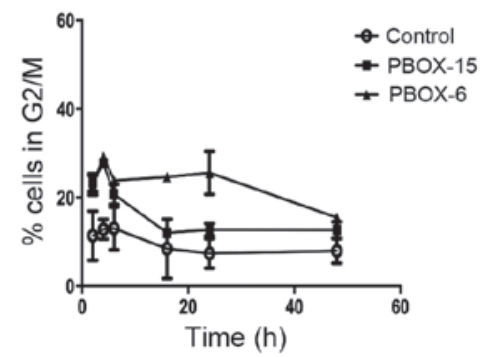

E

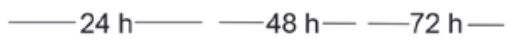

con veh P6 P15 veh P6 P15 veh P6 P15

PARP $116 \mathrm{kDa}$

$\beta$-actin $42 \mathrm{kDa}$
B

Ca9.22

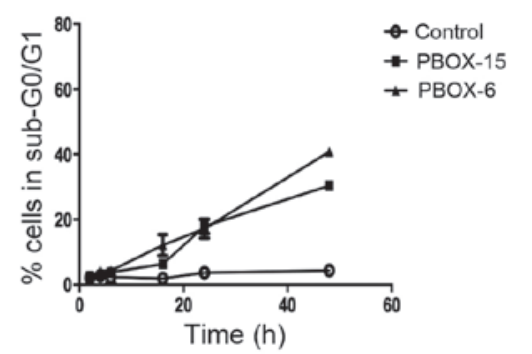

D

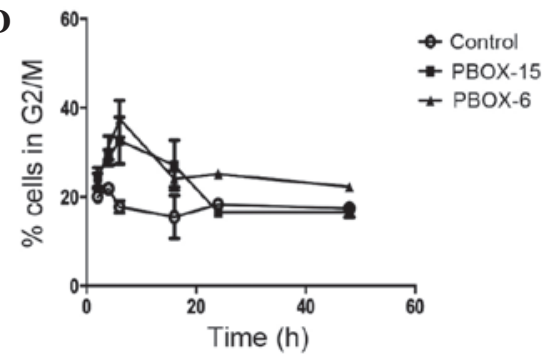

F

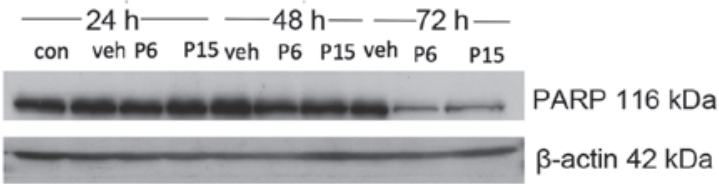

Figure 4. Pyrrolo-1,5-benzoxazepines (PBOX)-6 and PBOX-15 reduced proliferation of TR146 and Ca9.22 cells through induction of $\mathrm{G}_{2} / \mathrm{M}$ cell cycle arrest and cellular apoptosis. The TR146 and Ca9.22 cells were treated with $10 \mu \mathrm{M}$ PBOX-6, and $1 \mu \mathrm{M}$ PBOX-15 at various time points for up to $72 \mathrm{~h}$. The values are presented as the mean \pm standard error of the mean for three independent experiments. (A and B) Cells in the sub- $\mathrm{G}_{0} / \mathrm{G}_{1}$ phase with $<2 \mathrm{~N}$ quantities of

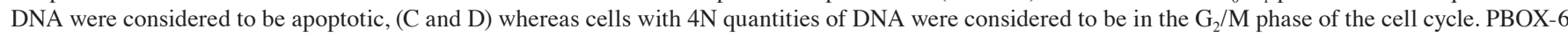
and PBOX-15 reduced full length poly (ADP ribose) polymerase (PARP) in Ca9.22 and TR146 cells. Both cell lines were treated with either vehicle (1\% (v/v) EtOH), $10 \mu \mathrm{M}$ PBOX-6, or $1 \mu \mathrm{M}$ PBOX-15 for the indicated times. (E and F) PARP degradation was assessed by western blot analysis using monoclonal antibodies targeting PARP, or loading control $\beta$-actin, followed by horseradish peroxidase (HRP)-conjugated anti-mouse secondary antibodies. The blots are representative of experiments repeated three times.

in numerous human tumour cell lines, and to have anti-cancer properties in various cell culture systems, animal models, and clinical samples $(11,17)$. In addition to inducing apoptosis in various cancer cell types, PBOX-6 and -15 possess the added benefit of inducing cytotoxicity in multi drug-resistant cancer cells (18).

The present study demonstrated that PBOX compounds were capable of reducing the proliferation of OC cell lines TR146 and $\mathrm{Ca} 9.22$, with $\mathrm{EC}_{50}$ values of $35 \pm 2.7 \mu \mathrm{M}$ and $2.6 \pm 1 \mu \mathrm{M}$ for PBOX-6, and $470 \pm 86 \mathrm{nM}$ and $83 \pm 32 \mathrm{nM}$ for PBOX-15. These values are within a range previously observed in other cancer cell lines exposed to PBOX compounds, including K562 chronic myeloid leukemia cells, A2780 ovarian carcinoma cells, and various cancerous mammary cells $(9,16,17)$. PBOX-15, as previously reported, is the more potent of the two compounds, a result that was confirmed in the present study in both cell lines tested, as demonstrated by the order of magnitude of difference in the calculated $\mathrm{EC}_{50}$ values. Significant variation in the sensitivity of each cell type to PBOX treatment was also observed. The Ca9.22 gingiva cell line was sensitive to both PBOX-15 and PBOX-6, and had significantly lower $\mathrm{EC}_{50}$ values, as compared with the TR146 buccal cell line. The observed variation in efficacy of the PBOXs in the two experimental cell lines suggests a phenotypic or genotypic factor may be involved. In OSCC, $\sim 50 \%$ of cases are associated with a mutation in the p53 gene, which results in deleterious phenotypic manifestations and impaired p53 function. The Ca9.22 cells have a known p53 mutation (19), whereas the TR146 cells have no known p53 mutation. Previous studies have reported the influence of p53 in modifying drug efficacy and function in cancer cells $(20,21)$.

The disassembly of the microtubule network in other cancer cell lines following treatment with PBOX-6 and PBOX-15 suggested that the compounds act as microtubule depolymerizing agents (13). To examine this hypothesis in OSCC, the Ca9.22 and TR146 cells were treated with various concentrations of PBOX-6 and PBOX-15. The results of the present study were concordant with previous studies, demonstrating that both PBOX compounds caused disassembly of tubulin following $24 \mathrm{~h}$ treatment in vitro $(13,22)$. In the case of the control compounds, nocodazole depolymerised tubulin, whereas treatment with paclitaxel resulted in tubulin aggregation through polymerisation. PBOX-15, the more potent of the two compounds, was effective at disrupting tubulin at $1 \mu \mathrm{M}$ in both cell lines, whereas PBOX-6-mediated depolymerisation was only observed at concentrations of $10 \mu \mathrm{M}$.

This inhibition of tubulin assembly is likely to be the cause of cell death following treatment with the PBOX compounds (13). Tubulin is a key protein in spindle formation during the cell cycle. A mechanism known as the spindle 
assembly checkpoint is activated during metaphase in the cell cycle (23). In the presence of tubulin breakdown and loss of spindle tension, the cell will not be able to continue into anaphase. In order to determine part of the mechanism underlying the response of OSCC cells to PBOX treatment, the effects of PBOX-6 and PBOX-15 on the cell cycle were examined. The PBOXs caused a time-dependent accumulation of cells in $\mathrm{G}_{2} / \mathrm{M}$ phase, as early as $4 \mathrm{~h}$ in TR146 cells, and $8 \mathrm{~h}$ in Ca9.22 cells. This was followed by an increase in the number of cells in sub- $\mathrm{G}_{0} / \mathrm{G}_{1}$ phase, indicative of apoptosis and a concomitant decrease in the percentage of cells in $\mathrm{G}_{2} / \mathrm{M}$. To confirm the mechanism of cell death, degradation of the DNA repair enzyme PARP, which is indicative of apoptosis, was examined. A decrease in the expression levels of the full-length $116 \mathrm{kDa}$ PARP was evident in both cell lines following treatment with both compounds after $72 \mathrm{~h}$, suggesting PARP had been cleaved. The decrease in full-length PARP in the Ca9.22 cell line was more prominent than in the TR146 cell line, demonstrating an increased sensitivity of the Ca9.22 cells to the compounds as it also increased the $\mathrm{EC}_{50}$ values obtained using this cell line.

The results of the present study indicated that PBOX-6, and its more potent analogue PBOX-15, may prove effective in the treatment of OSCC. The present study has shown that PBOX-6 and PBOX-15 depolymerise their molecular target, tubulin, resulting in cell death through apoptosis in OSCC cell lines. Given the prevalence of OSCC, the use of PBOX compounds as topical agents may be a potential therapeutic strategy for this disease. PBOX compounds used alone or in combination with other antineoplastic agents may prove useful in the treatment of OSCC.

\section{Acknowledgements}

The authors of the present study are thankful to the Dublin Dental University Hospital and Trinity College Dublin for funding this study through the 1252 initiative. An abstract describing this work was presented at the 23rd Biennial Congress of the European Association for Cancer Research.

\section{References}

1. Zhang L, Zhou X, Yao X, Wu Y and Zhang Q: Oral tongue cancer patients show a better overall survival than base of tongue cancer patients. J Cancer Res Clin Oncol 138: 341-346, 2012.

2. Arosarena OA, Madsen M and Haug R: Special considerations with floor of mouth and tongue cancer. Oral Maxillofac Surg Clin North Am 18: 521-531, 2006.

3. Beenken SW and Urist MM: Head and Neck Tumors. Current surgical diagnosis and treatment. L.W. Way, G.M. Doherty (Eds.). Lange Medical Books/McGraw-Hill, New York. 282-297, 2003.
4. World Health Organisation: World Cancer Report 2008.

5. National Cancer Research Institute: Surveillance, Epidemiology, and End Results (SEER) program- 2004.

6. Andreadis C, Vahtsevanos K, Sidiras T, Thomaidis I, Antoniadis K and Mouratidou D: 5-Fluorouracil and cisplatin in the treatment of advanced oral cancer. Oral Oncol 39: 380-385, 2003.

7. Galluzzi L, Senovilla L, Vitale I, et al: Molecular mechanisms of cisplatin resistance. Oncogene 31: 1869-1883, 2012.

8. Zhang N, Yin Y, Xu SJ and Chen WS: 5-Fluorouracil: Mechanisms of resistance and reversal strategies. Molecules 13: 1551-1569, 2008.

9. Nathwani SM, Butler S, Fayne D, et al: Novel microtubule-targeting agents, pyrrolo-1,5-benzoxazepines, induce apoptosis in multi-drug-resistant cancer cells. Cancer Chemother Pharmacol 66: 585-596, 2010.

10. McElligott AM, Maginn EN, Greene LM, et al: The novel tubulin-targeting agent pyrrolo-1,5-benzoxazepine-15 induces apoptosis in poor prognostic subgroups of chronic lymphocytic leukemia. Cancer Res 69: 8366-8375, 2009.

11. Bright SA, McElligott AM, O'Connell JW, et al: Novel pyrrolo-1,5-benzoxazepine compounds display significant activity against resistant chronic myeloid leukaemia cells in vitro, in ex vivo patient samples and in vivo. Br J Cancer 102: 1474-1482, 2010.

12. Maginn EN, Browne PV, Hayden P, et al: PBOX-15, a novel microtubule targeting agent, induces apoptosis, upregulates death receptors, and potentiates TRAIL-mediated apoptosis in multiple myeloma cells. Br J Cancer 104: 281-289, 2011.

13. Li YM and Broome JD: Arsenic targets tubulins to induce apoptosis in myeloid leukemia cells. Cancer Res 59: 776-780, 1999.

14. Woods CM, Zhu J, McQueney PA, Bollag D and Lazarides E: Taxol-induced mitotic block triggers rapid onset of a p53-independent apoptotic pathway. Mol Med 1: 506-526, 1995.

15. Mulligan JM, Greene LM, Cloonan S, et al: Identification of tubulin as the molecular target of proapoptoticpyrrolo-1,5-benzoxazepines. Mol Pharmacol 70: 60-70, 2006.

16. Greene LM, Fleeton M, Mulligan J, et al: The pyrrolo-1,5-benzoxazepine, PBOX-6, inhibits the growth of breast cancer cells in vitro independent of estrogen receptor status and inhibits breast tumour growth in vivo. Oncol Rep 14: 1357-1363, 2005.

17. Nathwani SM, Cloonan SM, Stronach M, et al: Novel microtubule-targeting agents, pyrrolo-1,5-benzoxazepines, induce cell cycle arrest and apoptosis in prostate cancer cells. Oncol Rep 24: 1499-1507, 2010.

18. Mc Gee MM, Campiani G, Ramunno A, et al: Activation of the c-Jun N-terminal kinase (JNK) signaling pathway is essential during PBOX-6-induced apoptosis in chronic myelogenous leukemia (CML) cells. J Biol Chem 277: 18383-18389, 2002.

19. Kaneda Y, Shimamoto H, Matsumura K, et al: Role of caspase 8 as a determinant in chemosensitivity of p53-mutated head and neck squamous cell carcinoma cell lines. J Med Dent Sci 53: 57-66, 2006.

20. Bunz F, Hwang PM, Torrance C, et al: Disruption of p53 in human cancer cells alters the responses to therapeutic agents. J Clin Invest 104: 263-269, 1999.

21. Jackson JG, Pant V, Li Q, Chang LL, Quintas-Cardama A, Garza D, Tavana O, Yang P, Manshouri T, Li Y, El-Naggar AK, and Lozano G: p53-mediated senescence impairs the apoptotic response to chemotherapy and clinical outcome in breast cancer. Cancer Cell 21, 793-806, 2012.

22. Verma, NK, Dempsey E, Conroy J, et al: A new microtubule-targeting compound PBOX-15 inhibits T-cell migration via post-translational modifications of tubulin. J Mol Med 86, 457-469. 2008.

23. Rudner AD and Murray AW: The spindle assembly checkpoint. Curr Opin Cell Biol 8: 773-780, 1996. 